\title{
The Value of Citations in Academic Disciplines
}

\author{
Ella Byrne ${ }^{1}$
}

Writing across the University of Alberta, $2021^{2}$

Volume 2, pp. 29-32

Published December 2021

Keywords: citation, academic writing, discourse community, writing in disciplines

Citation is a form of accrediting the author of a source. It acts as a unifying force in disciplines and illustrates an individual's knowledge in their field of study (Nesi, 2021). Citations are used in academic situations as a means of avoiding plagiarism because no words or ideas can be classified as innate. Due to this, writing can be classified as a social activity and in a sense, it brings people in disciplinary communities together (Roozen, 2015). Citation is an integral aspect of writing in academia, and it can be noted that citation varies from discipline to discipline (Hyland, 1999). This can show that awareness of citations informs both the rhetoric in one's discipline and the individual in an academic community.

Before enrolling in Writing Studies 101, I was unaware of the importance of source-based writing and the role of citation. In fact, I found activities pertaining to citation tedious and boring. I was troubled by the idea that I needed to tag a citation to every statement, even those that I may classify as preliminary or common knowledge. However, after the completion of the first assignment that prompted me to investigate the rhetorical situation of research articles within my discipline of neuroscience, I became aware of the reasons why citation is not only necessary but beneficial both as a means of building rhetoric and showing commitment to an individual's discipline.

\section{The Use of Citation in Rhetoric}

To obtain an audience's accordance, an author must utilize successful rhetoric (Ting, 2018). A dominant strategy utilized in all levels of academia is Aristotle's three persuasive appeals: ethos, pathos, and logos, which appeal to ethics, emotions, and logic respectively (Ting, 2018). Citations that fall into the appeal to ethos demonstrate the author's credibility,

${ }^{1}$ Correspondence: Ella Byrne (embyrne@ualberta.ca)

${ }^{2}$ Writing across the University of Alberta (WAUA) publishes undergraduate student writing from Writing Studies courses at the University of Alberta. You can find WAUA online at writingacrossuofa.ca. 
knowledge, and dedication to research on their topic of study (Nesi, 2021). Thus, citations directly contribute to the persuasive appeal of an author's argument. Information that an author provides may seem appealing, and accordingly, may align with a reader's pre-existing opinions, but it is also a reader's responsibility to be skeptical and wary of the origin and accuracy of information (Snap Language, 2016). Without citations, a reader is unable to verify whether the information provided is correct and, ultimately, whether the rhetoric of an otherwise sound argument is lost or not. As stated, prior to commencing this Writing Studies class, I had little respect for the practice of using and citing sources. Through course readings and materials, I have developed an appreciation for the integration of sources in all forms of writing. I found that while reading course material, I had a greater appreciation and sense of trust in articles that actively utilized citations after each claim. The integration of sources demonstrated that the author's claims are supported by published literature, which allowed me to recognize the credibility of the author.

Understanding your topic of study is fundamental in effective academic writing (Irvin, 2010), and citations ensure an individual's audience of their commitment to understanding. In university-level writing courses, a professor is more likely to ask for sources and citations, which in turn would exemplify that the student can synthesize information, develop opinions and establish a connection between their topic and the sources utilized (Nesi, 2021). This also allows the student to develop necessary skills that will ultimately be used in professional writing. In my discipline of neuroscience, I am immersed into the realm of research which calls on me to utilize different forms of sources and citations such as background sources to establish definitions and the context of the study (Bizup, 2008). In my biology class, I remember feeling frustrated because I was asked to find and cite a scholarly source for the definition of virulence, a term my peers and I are familiar with. This query was difficult to understand at the time, but through reflection, knowledge obtained from this course, and by delving into my own research on citations, I became aware that citations are needed for background sources as they define the jargon that I may be familiar with, but a reader outside of my discipline, may not be. It is my job as an individual in academia to inform my audience of the information and to reassure them that the information which I am providing is correct and verifiable. This ultimately builds and adds to the overall credibility and persuasiveness of my claim, thesis, or findings.

\section{The Use of Citations to Immerse an Individual into an Academic Community}

Bizup claims there are four distinct types of sources used and observed through different academic disciplines: background, exhibition, argument and method sources, each of which has its own purpose (Bizup, 2008). Background sources are presented as factual, baseline, or in doubt. Exhibition sources are interpreted and investigated by the author 
presenting the source. Argument sources are integrated to support or contradict an author's claim and ultimately build a persuasive argument. Lastly, method sources are those that present preexisting methodology or research procedures (Nesi, 2021). Through this discovery, it became easy to understand how the type of sources used in certain disciplines are characteristic and reflective of the nature of that discipline. Through reading three research articles within my discipline of neuroscience, I noticed a high degree of background sources, argument sources, and method sources in this respective order. This intuitive use and flow of sources build to the general genre of research articles in neuroscience; thus, allowing for such a distinctive yet similar layout of each article.

Moreover, both the citation style and frequency of citations differ across disciplines, as shown in a study carried out by Hilary Nesi (2021). Nesi (2021) found that the frequency of 'name (date) verb' integral citations per million words increased drastically through progressive years of undergraduate studies in four academic disciplines. Moreover, the frequency of integral citations was the highest in life sciences $(245.01-717.23)$, followed by social sciences $(166.73$ - 526.46) and arts and humanities (75.13 - 287.15). These results show the characteristic high frequency of integral citations within the discipline of science and the relatively low frequency of integral citations in arts and humanities and physical sciences (Nesi, 2021). This study shows that the frequency of citations is consistent in distinctive disciplines and plays a part in defining the discipline. Indeed, through reading articles within my discipline of neuroscience, I observed a significantly high frequency of integral citations. At first glance, I felt overwhelmed by the influx of citations, but I persevered, and within a short period of time, this characteristic high frequency became something I not only came to appreciate but also respect.

Considering the observed flow of specific sources and the high frequency of integral citations within neuroscience research articles, I can conclude that there are characteristic methods used in neuroscience that agree with the scientific approach and the nature of inquiry of the discipline. I am passionate about neuroscience, and therefore, I believe it to be important for me to immerse myself in the community of neuroscience by adapting to the citation styles and applications used to demonstrate my commitment to the academic discipline.

\section{Conclusion}

Ultimately, citations are infinitely important to ensure the integrity, credibility, and persuasive characteristics of articles in all academic disciplines. Conforming to the citation styles and standards utilized in a discipline is essential in immersing an individual into their discipline. This Writing Studies course has pushed me to recognize the value that citations 
bring to my writing, and I am confident the skills I have acquired will be utilized to their full potential in future endeavours.

\section{References}

Bizup, J. (2008). BEAM: A rhetorical vocabulary for teaching research-based writing. Rhetoric Review, 27(1), 72-86. https://doi.org/10.1080/07350190701738858

Hyland, K. (1999). Academic attribution: citation and the construction of disciplinary knowledge. Applied Linguistics, 20(3), 341-367. https://doi.org/10.1093/applin/20.3.341

Irvin, L. L. (2010). What Is "academic" writing? In C. Lowe \& P. Zemliansky (Eds.), Writing spaces: Readings on writing (Vol. 1, pp. 3-17). Parlor Press.

Nesi, H. (2021). Sources for courses: Metadiscourse and the role of citation in student writing. Lingua. International Review of General Linguistics. Revue Internationale de Linguistique Generale, 253(103040), 103040. https://doi.org/10.1016/j.lingua.2021.103040

Roozen, K., Estrem, H., Lunsford, A. A., Bazerman, C., Dryer, D. B., Scott, T., Inoue, A. B., Duffy, J., Brooke, C., \& Grabill, J. T. (2015). Concept 1: Writing is a social and rhetorical activity. In L. Adler-Kassner \& E. Wardle (Eds.), Naming what we know: Threshold concepts of writing studies (pp. 17-34). Utah State University Press.

Snap Language. (2016, June 23). Analyzing the Argument - Part 1 of 2. YouTube. https://youtu.be/pP8dWURrEF0

Ting, S. (2018). Ethos, logos, and pathos in university students' informal requests. GEMA Online Journal of Language Studies, 18(1), 234-251. http://doi.org/10.17576/gema-2018-1801-14

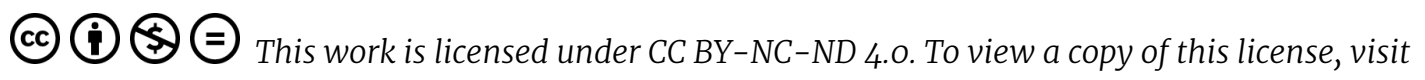
https://creativecommons.org/licenses/by-nc-nd/4.0. 